\title{
O MERCOSUL E AS LINHAS GERAIS DE SEU SISTEMA DE SOLUÇÃO DE CONTROVÉRSIAS
}

\section{EL MERCOSUR Y LAS LÍNEAS GENERALES DE SU SISTEMA DE SOLUCIÓN DE CONTROVERSIAS}

\section{Raphael Carvalho de Vasconcelos}

\begin{abstract}
Resumo: Sistemas de solução de controvérsias são fundamentais à manutenção da coerência do direito de organizações internacionais. O MERCOSUL contou com mecanismos institucionalizados para dirimir litígios desde sua gênese. No período de vigência do Protocolo de Brasília, por exemplo, todos os laudos arbitrais prolatados foram cumpridos. A existência de uma instância arbitral permanente e o acesso de indivíduos à competência consultiva são os pontos mais marcantes do atual regime do Protocolo de Olivos. Este trabalho possui características marcadamente descritivas e dogmáticas. Decidiu-se por não adotar a sistemática científica tradicional fundada em problema e hipótese de partida. Buscouse consolidar em poucas páginas as questões práticas mais relevantes do atual sistema. Como mensagem conclusiva, observa-se a grande expectativa criada em torno de entrada em vigor do Protocolo de Olivos II e do fortalecimento institucional do órgão máximo do sistema solução de controvérsias regional.
\end{abstract}

Resumen: Sistemas de solución de controversias son fundamentales para el mantenimiento de la coherencia del derecho de organizaciones internacionales. El MERCOSUR tiene mecanismos institucionales para la solución de litigios desde el principio. En el periodo de vigencia del Protocolo de Brasilia, por ejemplo, todos los laudos arbitrales fueron cumplidos. La existencia de una instancia arbitral permanente y el acceso de individuos a la competencia consultiva son los puntos más remarcables en el actual régimen del Protocolo de Olivos. Este trabajo

* O presente trabalho propõe uma releitura do artigo VASCONCELOS, Raphael Carvalho. "O Sistema de Solução de Controvérsias do MERCOSUL”. Ética e Filosofia Política. 2009, p. 1-30. A perspectiva original de 2009 não se manteve intacta após o mandato exercido pelo autor por quatro anos à frente da Secretaria do Tribunal Permanente de Revisão do MERCOSUL.

** Mestre e Doutor pela Universidade do Estado do Rio de Janeiro. Mestre e Doutor pela Universidade de São Paulo. Professor da Universidade do Estado do Rio de Janeiro e da Universidade Federal Rural do Rio de Janeiro. Editor-chefe do Panorama of Brazilian Law. Advogado e Consultor. E-mail: rvasconcelos@raphaelvasconcelos.com 
tiene características descriptivas y dogmáticas. Se decidió no adoptar el sistema científico tradicional basado en un problema y en una hipótesis de partida. Se buscó consolidar en pocas páginas las cuestiones prácticas más importantes del actual sistema. En mensaje de conclusión, se observa la gran expectativa creada por la inminente vigencia del Protocolo de Olivos II y por el fortalecimiento del órgano máximo del sistema de solución de controversias regional.

Palavras-chave: MERCOSUL, Solução de controvérsias, Protocolo de Olivos Palabras clave: MERCOSUR, Solución de controvérsias, Protocolo de Olivos

\section{INTRODUÇÃO}

Sistemas de solução de controvérsias são inerentes a organizações internacionais. Sustentou-se em trabalhos anteriores, inclusive, a impossibilidade de se reconhecer como organização internacional uma estrutura institucional desprovida de mecanismos de solução de litígios. $\mathrm{O}$ anexo III do Tratado de Assunção já previa para o MERCOSUL um esquema rudimentar para dirimir controvérsias.

A precariedade original foi logo substituída pelo Protocolo de Brasília e, posteriormente, pelo Protocolo de Olivos. No sistema atual, a legitimidade ativa está concentrada nos estados - ainda que artificialmente também esteja previsto o acesso de particulares - e o direito do MERCOSUL como um todo encontra-se inserido em seu objeto. O Tribunal Permanente de Revisão e as opiniões consultivas podem ser apontados como os aspectos mais inovadores e importantes do atual sistema.

$\mathrm{O}$ estudo aqui consolidado tem características extremamente descritivas e dogmáticas. Busca-se fixar um panorama simples do funcionamento do sistema de solução de litígios do MERCOSUL temperado com considerações sobre perspectivas teóricas atuais sobre o assunto. Não se trabalhou com o esquema científico fundado em problema e hipótese de partida. Não era essa a finalidade do artigo.

Na primeira parte do trabalho, a eficácia das normas internacionais se apresenta como tema para reflexão e o papel dos tribunais internacionais ganha relevo. Um panorama histórico do sistema de solução de controvérsias do MERCOSUL é apresentado em seguida para introduzir os aspectos mais dogmáticos de seu funcionamento atual. Os contornos dos laudos arbitrais são objeto da parte seguinte que antecede análise, igualmente dogmática, das chamadas medidas compensatórias permitidas pelo mecanismo. 


\section{A EFICÁCIA DAS NORMAS INTERNACIONAIS}

A eficácia de uma norma na ordem jurídica interna é garantida pela existência de um controle jurisdicional capaz de resguardar seu cumprimento. O sistema se sustenta, na verdade, quando garante a aplicação das regras instituídas por meio de sanções capazes de coibir seu descumprimento.

$\mathrm{Na}$ ordem jurídica internacional, a eficácia da norma raramente é garantida pela possibilidade de aplicação de sanções e decorre normalmente do próprio interesse dos sujeitos de direito internacional ${ }^{1}$. No contexto específico das organizações de integração, o controle da legalidade se faz necessário à delimitação da interpretação das normas e ao repúdio a violações aos instrumentos comuns ${ }^{2}$.

Em organizações regionais de cunho eminentemente comercial, esse controle seria especialmente fundamental ao restabelecimento do equilíbrio entre as partes contratantes ${ }^{3}$. A sanção imposta não deve ser o fim, mas o meio para garantir o controle da aplicação das normas, requisito à própria existência de uma organização ${ }^{4}$.

No MERCOSUL referido controle é feito atualmente de duas formas distintas e independentes. De um lado, a exegese da normativa regional é feita pelos tribunais nacionais, que atuam de forma autônoma, e, de outro lado, pelo mecanismo comum de solução de controvérsias instituído pelo Protocolo de Olivos.

\section{HISTÓRICODOSISTEMADESOLUÇÃODECONTROVÉRSIAS DO MERCOSUL}

A prerrogativa dada aos estados de não serem obrigados à submissão a outra jurisdição que não a sua própria, quando considerados os clássicos conceitos de soberania, favorece os meios internacionais para a solução de controvérsias, sejam eles diplomáticos, políticos ou jurisdicionais ${ }^{5}$.

1 Nesse sentido, ACCIOLY, Hildebrando. Manual de direito internacional público. São Paulo: Saraiva, 1972 p. 129 e BAPTISTA, Luiz Olavo. "As soluções de divergências no MERCOSUL". In: Basso, Maristela. MERCOSUL seus efeitos jurídicos, econômicos e políticos nos Estados-membros. Porto Alegre: Livraria do Advogado, 1995, p. 91. Para dirimir quaisquer dúvidas ortográficas, ressalta-se a opção pelo uso da inicial minúscula no termo "estado" em linha com pensamento internacionalista que, sem negar a importância desse ator da ordem internacional, relativiza sua centralidade. Nesse sentido, CASELLA, Paulo Borba. BRIC: Uma perspectiva de cooperação internacional. São Paulo: Atlas, 2011. p. 1-02.

2 CASELLA, Paulo Borba. MERCOSUL exigências e perspectivas. São Paulo: Ltr, 1996, p. 168.

3 PEREIRA, Ana Cristina Paulo. Direito institucional e material do MERCOSUL. Rio de Janeiro: Lumen Juris, 2005, p. 86.

4 RUÍZ DIAZ LABRANO, Roberto. Hacia un tribunal de caracter supranacional en el MERCOSUR. Desafíos del MERCOSUR. Buenos Aires: Ciudad Argentina, p.159-175, 1997. p. 160.

5 Sobre a relação existente entre a soberania e os meios de solução de controvérsias entre estados, BAPTISTA, Luiz Olavo. "Sistemas para solução de divergências nas instituições de integração e o MERCOSUL”. In: MAGALHÃES, José Carlos \& MERCADANTE, Araminta de Azevedo (ed.). Solução e prevenção de litígios internacionais. Porto Alegre: Livraria do Advogado, 
Dentre os meios jurisdicionais de solução de conflitos internacionais encontram-se os judiciais e os arbitrais. Cumpre ressaltar que as decisões emanadas de órgãos jurisdicionais apenas são obrigatórias aos estados a que se dirigem quando a competência jurisdicional houver sido expressamente reconhecida ${ }^{6}$.

No caso do MERCOSUL, o Protocolo de Brasília já estipulava em seu artigo 8 que os estados reconheciam a jurisdição dos Tribunais Arbitrais Ad Hoc como obrigatória. O atual sistema de solução de controvérsias regional possui dispositivo semelhante contido no artigo 33 do Protocolo de Olivos, o qual além da obrigatoriedade de jurisdição dos Tribunais Ad Hoc, reconhece também aquela do Tribunal Permanente de Revisão.

Pode-se dizer que houve, ao longo do tempo, um amadurecimento dos procedimentos de solução de litígios no MERCOSUL, tendo em vista que os meios diplomáticos e políticos, ainda que válidos, em uso e de extrema importância ${ }^{7}$, assistem, principalmente após a entrada em vigor do Protocolo de Olivos, ao desenvolvimento de um sistema mais claramente jurisdicional.

Quanto à velocidade da evolução do sistema de solução de controvérsias do MERCOSUL, ainda que contundentes as críticas relacionadas à morosidade de seu aperfeiçoamento, sua construção apresenta constância e não esconde o caráter programático do projeto ${ }^{8}$.

\subsection{O Tratado de Assunção}

A necessidade de criação de um sistema regional para solução de controvérsias fez parte das negociações relacionadas à elaboração do direito originário do MERCOSUL. O tema foi, dessa forma, incorporado ao Tratado de Assunção ${ }^{9}$ que previu, em seu anexo III, o primeiro procedimento de solução de controvérsias da organização de integração regional, o qual se sustentava de forma eminentemente política e continha trâmite extremamente simples.

1999, p. 338 e 441; FERRAJOLI, Luigi. A Soberania no Mundo Moderno. São Paulo: Martins Fontes, 2002.p. 48.

6 A exemplo do estabelecido na "Cláusula Raul Fernandes" do Estatuto da Corte Internacional de Justiça.

7 BAPTISTA, Luiz Olavo. O MERCOSUL, suas instituições e ordenamento jurídico. São Paulo: Ltr, 1998, p. 147.

8 COSTA, Elizabeth Accioly Rodrigues da. "O sistema de solução de controvérsias do MERCOSUL consoante a previsão do artigo 44 do protocolo de Ouro Preto: análise comparativa de sistema de solução de controvérsias em blocos econômicos e propostas para o sistema permanente do MERCOSUL". [Tese de Doutorado]. Faculdade de Direito da Universidade de São Paulo, 2003, p. 255.

9 Firmado em 26 de março de 1991 na cidade de Assunção, capital do Paraguai, aprovado pelo congresso nacional por meio do decreto legislativo $\mathrm{n}^{\circ}$. 197 de 25 de setembro de 1991, texto publicado anexo ao decreto executivo $\mathrm{n}^{\circ}$. 350 de 21 de novembro de 1991 e internacionalmente em vigor, conforme disposições de seu artigo 19, em 29 de novembro de 1991. 
Segundo o mencionado procedimento, haveria inicialmente a tentativa de se encontrar uma solução para os litígios por meio de negociações diretas entre os estados. No caso da impossibilidade de uma solução pela via direta, o Grupo do Mercado Comum - GMC deveria, por consenso, emitir uma recomendação.

Em caso de falta de consenso ou descumprimento da recomendação do GMC, o Conselho do Mercado Comum deveria, também por consenso, pronunciar-se a respeito por meio da adoção das recomendações que julgasse pertinentes.

O procedimento previsto no anexo III do Tratado de Assunção, o qual nunca foi utilizado, foi extinto em 1993 com a entrada em vigor do Protocolo de Brasília para Solução de Controvérsias.

\subsection{O Protocolo de Brasília}

O procedimento do Protocolo de Brasília ${ }^{10}$ foi concebido para, dando sequência ao desenho feito pelo Tratado de Assunção $0^{11}$, viger até a estruturação institucional definitiva do MERCOSUL, mas continuou em vigor, entretanto, após a assinatura do Protocolo de Ouro Preto em $1994^{12}$.

O próprio preâmbulo do Protocolo de Brasília indicava claramente tratar-se de um sistema provisório para a solução de litígios e referia-se ao período de transição citando, inclusive, o artigo 3 do anexo III do Tratado de Assunção, de onde pode-se extrair que deveria ter terminado em 31 de dezembro de 1994.

O mecanismo previa a solução de disputas por meio da realização de três fases. A primeira delas, instituída no capítulo II do protocolo, consistia em uma fase política obrigatória, baseada em negociações diretas entre os estados. No caso de impossibilidade de composição havia, conforme disposto no capítulo III, a interferência do Grupo Mercado Comum, o qual exercia papel conciliador e formulava recomendações. Fracassadas as tentativas de solução diplomática e política, constituía-se um Tribunal Arbitral Ad Hoc, o qual deveria proferir um laudo definitivo.

Pode-se afirmar que a solução de litígios no MERCOSUL iniciou - no mecanismo flexível, célere, obrigatório e não permanente ${ }^{13}$ previsto no Protocolo de Brasília - sua evolução em direção a um sistema

10 Firmado em Brasília em 17 de dezembro de 1991, aprovado pelo congresso nacional por meio do decreto legislativo $\mathrm{n}^{\circ} .88$ de 01 de dezembro de 1992, texto publicado anexo ao decreto executivo $\mathrm{n}^{\circ} .922$ de 10 de setembro de 1993 e internacionalmente em vigor, conforme disposições de seu artigo 33, em 24 de abril de 1993.

11 BAPTISTA, Luiz Olavo. Op. cit., p. 152.

12 Firmado em Ouro Preto em 17 de dezembro de 1994, aprovado pelo congresso nacional por meio do decreto legislativo $\mathrm{n}^{\circ} .188$ de 15 de dezembro de 1995, texto publicado anexo ao decreto executivo $\mathrm{n}^{\circ} .1901$ de 09 de maio de 1996 e em vigor para o Brasil em 16 de fevereiro de 1996, data do depósito da carta de ratificação correspondente.

13 ETCHEVERRY, Raul Aníbal. MERCOSUR negocios y empresas. Buenos Aires: Ciudad Argentina, 2001, p. 127. 
jurisdicional em detrimento daquele marcadamente político do direito internacional público geral.

Os procedimentos contidos no Protocolo de Brasília apresentavamse ao mesmo tempo, entretanto, como um avanço na solução de litígios no âmbito regional e incompatíveis com um processo de integração econômica ${ }^{14}$.

Os laudos em Brasília eram, conforme disposição do artigo 21, inapeláveis e poderiam ser objeto apenas de pedido, dirigido ao Tribunal Ad Hoc que proferiu a decisão, de esclarecimento ou de interpretação da forma como deveria ocorrer o cumprimento ${ }^{15}$. Dez casos foram processados na forma do Protocolo de Brasília até a entrada em vigor do Protocolo de Olivos para a Solução de Controvérsias em 2004.

\subsection{O Protocolo de Ouro Preto}

O Protocolo de Ouro Preto não alterou o mecanismo regido pelo Protocolo de Brasília mesmo tendo criado em seu artigo $21 \mathrm{um}$ procedimento alternativo para a solução de litígios relacionados a matérias de política comercial ${ }^{16}$. Pode-se dizer que o Protocolo de Ouro Preto garantiu a perpetuação do procedimento de Brasília, substituído pelo Protocolo de Olivos em $2004^{17}$, após mais de uma década de reconhecidos serviços prestados ao processo de integração regional ${ }^{18}$.

Observa-se, ainda, que a única inovação consistente trazida pelo Protocolo de Ouro Preto reside em seu artigo 21 que estabelece a alternativa dada aos estados e aos particulares de levarem suas reclamações à Comissão de Comércio do MERCOSUL, que deve, por sua vez, apresentar uma solução para o caso de forma consensual e eventualmente com auxílio de um comitê técnico ${ }^{19}$.

No caso de impossibilidade de obtenção de uma decisão por consenso, a matéria deve ser levada ao Grupo do Mercado Comum que deve, também mediante consenso, solucionar o litígio.

Uma solução consensual para a reclamação, proferida tanto pela Comissão quanto pelo Grupo, vincula o estado reclamado, o qual poderá ser acionado na forma prevista pelo mecanismo de solução de controvérsias em caso de descumprimento. Gize-se que a falta de

14 CASELLA, Paulo Borba. Direito internacional: vertente jurídica da globalização. Porto Alegre: Síntese, 2000, p. 61.

15 RANGEL, Vicente Marotta. "Solução de controvérsias após Ouro Preto". In: Casella, Paulo Borba (ed.). Contratos internacionais e direito econômico no MERCOSUL após o término do período de transição. São Paulo: Ltr, 1996.p. 701.

16 Ibíd., p. 694.

17 Firmado na Argentina em 18 de fevereiro de 2002, aprovado pelo congresso nacional por meio do decreto legislativo $\mathrm{n}^{\circ} .712$ de 14 de outubro de 2003 , texto publicado anexo ao decreto executivo $\mathrm{n}^{\circ} .4982$ de 09 de fevereiro de 2004 e internacionalmente em vigor em 01 de janeiro de 2004.

18 RANGEL, Vicente Marotta. Op. cit., p. 700.

19 O mecanismo instituído no artigo 21 obedece ao "Procedimento Geral para Reclamações Perante a Comissão de Comércio do MERCOSUL", anexo ao protocolo de Ouro Preto posteriormente regulamentado pela Decisão no. 18/02 do Conselho do Mercado Comum. 
decisão consensual também pode ensejar a provocação do mecanismo.

O procedimento previsto no artigo 21 do Protocolo de Ouro Preto está em vigor e continua podendo ser invocado nos casos de controvérsias relacionadas a questões de política comercial.

\subsection{O Protocolo de Olivos}

O mecanismo de solução de controvérsias disciplinado no Protocolo de Olivos, atual sistema de solução de controvérsias do MERCOSUL, é alvo de uma série de críticas, inclusive quanto à discutível necessidade de se criar um novo sistema provisório de solução de conflitos em substituição a um modelo considerado eficaz, caso daquele do Protocolo de Brasília.

De certo, nenhum dos signatários do Tratado de Assunção questionava a eficácia do mecanismo anterior. Todos os laudos arbitrais proferidos até a entrada em vigor da nova sistemática foram devidamente cumpridos. Os estados tampouco demonstravam interesse em aperfeiçoar o modelo intergovernamental, o que poderia justificar urgência em alterá-lo.

Em termos políticos, a crítica que se faz ao Protocolo de Olivos tem justamente a ver com seu caráter provisório, pois o novo mecanismo não estabeleceu o sistema permanente de solução de controvérsias do MERCOSUL.

$\mathrm{O}$ artigo 53 do protocolo faz, assim como fazia o preâmbulo do Protocolo de Brasília, expressa referência ao inciso 3 do anexo III do Tratado de Assunção e determina a revisão do mecanismo para que se estabeleça o Sistema Permanente de Solução de Controvérsias do MERCOSUL antes de "culminar o processo de convergência da tarifa externa comum", ou seja, da definitiva constituição do mercado comum.

As severas críticas doutrinárias residem, entretanto, nas inovações jurídicas estabelecidas pelo novo procedimento. As polêmicas se concentram principalmente naqueles dispositivos diretamente relacionadas à arbitragem e especificamente à criação do Tribunal Permanente de Revisão do MERCOSUL, órgão jurisdicional com sede na cidade de Assunção, no Paraguai, e dotado de competências e características únicas no direito internacional.

Ainda que parte da doutrina insista em questionar, por exemplo, a possibilidade de revisão de laudo arbitral pelo Tribunal Permanente de Revisão do MERCOSUL, a criação de uma corte arbitral permanente tem ampla acolhida doutrinária ${ }^{20}$.

Conforme mencionado, o órgão jurisdicional criado em Olivos possui competência recursal para as decisões prolatadas por tribunais arbitrais ad hoc no sistema de solução de controvérsias do MERCOSUL, mas não possui prerrogativas e características de um tribunal de

20 BAPTISTA, Luiz Olavo. Op. cit., p. 111. 
justiça. Nesse contexto, é de se observar que o caráter estritamente intergovernamental do MERCOSUL se encontra refletido em seu sistema de solução de controvérsias que transfere grande parte do peso da aplicação do direito regional ao judiciário dos estados ${ }^{21}$.

O sistema de olivos é arbitral. Esse dado precisa ser reafirmado à exaustão em resposta àqueles que questionam a moderação de seus membros ao decidir. Exigir postura de tribunal de justiça de um órgão arbitral denota falta de compreensão da estrutura do sistema de solução de controvérsias do MERCOSUL. No mesmo equívoco incorrem aqueles que criticam a possibilidade de revisão de laudo emitido por tribunais ad hoc. Esses últimos insistem em enquadrar soberanias nos parâmetros da arbitragem privada. Nos dois casos, as críticas decorrem de falhas nas premissas adotadas pelos pesquisadores ${ }^{22}$.

\section{O SISTEMA DE SOLUÇÃO DE CONTROVÉRSIAS DO MERCOSUL}

\subsection{Competência}

O sistema de solução de controvérsias do MERCOSUL foi desde sua criação organizado de forma a delimitar sua competência pelo objeto e pelas partes envolvidas no litígio.

A competência objetiva do mecanismo, conforme disposto no artigo 1 do Protocolo de Olivos, abrange todos os litígios relacionados às obrigações previstas em qualquer uma das fontes jurídicas do MERCOSUL, sejam elas originárias ou derivadas ${ }^{23}$. No tocante à competência subjetiva, possuem legitimidade ativa os estados, de forma plena e garantida no mesmo artigo 1, e os particulares, indiretamente e conforme disposto no capítulo XI do Protocolo.

Importante ressaltar que a legitimidade ativa do estado não está condicionada à demonstração de prejuízo, bastando a convicção de ter havido violação de norma regional por outro membro da organização, valendo, nesse caso, a própria não incorporação como violação.

Já no caso dos particulares, a legitimidade ativa tem como requisitos essenciais a prova de prejuízo e de nexo de causalidade entre o prejuízo e a violação incorrida, conforme dispõe o artigo 40

21 MERCADO COMUM DO SUL, MERCOSUL. Primeiro relatório sobre a aplicação do direito do MERCOSUL pelos tribunais nacionais. Montevideo: Secretaría do MERCOSUL, 2005, p. 125. 22 A versão original deste artigo, datada de 2009, é exemplo nítido de falha metodológica nas premissas de análise estabelecidas e é refutada, nesta parte específica, em sua integralidade.

23 O inciso 1 do artigo 1 do Protocolo de Olivos dispõe, "in verbis": "As controvérsias que surjam entre os Estados-partes sobre a interpretação, a aplicação ou o não cumprimento do Tratado de Assunção, do Protocolo de Ouro Preto, dos protocolos e acordos celebrados no marco do Tratado de Assunção, das Decisões do Conselho do Mercado Comum, das Resoluções do Grupo Mercado Comum e das Diretrizes da Comissão de Comércio do MERCOSUL serão submetidas aos procedimentos estabelecidos no presente Protocolo". 
do Protocolo de Olivos. A simples existência de violação não enseja legitimidade dos particulares para acionar o mecanismo ${ }^{24}$. No que se refere especificamente à legitimidade ativa de particulares, importante se faz ressaltar a necessidade de estado assumir como própria a reclamação do particular para que o litígio prospere no sistema. Não existe, em síntese, acesso direto de particular. Tem-se aqui, na verdade, exemplo claro de proteção diplomática necessária.

A legitimidade passiva do sistema de solução de controvérsias do MERCOSUL abrange apenas os estados, os quais seriam, portanto, os únicos passíveis de responsabilização na esfera internacional. Nem os particulares, nem os órgãos da organização de integração encontram-se entre os legitimados passivos do sistema do Protocolo de Olivos.

\subsection{Forum Shopping}

O Protocolo de Olivos criou no sistema de solução de controvérsias do MERCOSUL a possibilidade de os litígios abrangidos pelo sistema regional serem levados a outros mecanismos de solução de disputas. Tal hipótese surge, por exemplo, exatamente naqueles casos em que há competência concorrente entre o sistema do MERCOSUL e outro, como no da Organização Mundial do Comércio - OMC -, que é expressamente mencionada no inciso 2 do artigo 1 do Protocolo de Olivos.

A possibilidade criada visa claramente evitar a duplicidade de procedimentos e garantir o respeito à coisa julgada ${ }^{25}$, mas é objeto de severas críticas relacionadas à opção por não consagrar no sistema de solução de controvérsias a primazia do foro regional. Se por um lado o direito regional teve sua primazia reconhecida pelos tribunais ad hoc ${ }^{26}$, a primazia do foro regional não foi instituída pelo sistema de solução de controvérsias criado no Protocolo de Olivos, o que a nosso ver representa certa contradição.

O órgão jurisdicional deveria ser, a exemplo do ocorrido na gênese do processo de integração europeia, a base de todo o sistema, mas essa não foi a opção do MERCOSUL, já que a própria possibilidade de eleição de foro mostra-se totalmente incompatível com uma organização de integração.

Por outro lado, a referida solução constitui exemplo importante dos esforços necessários à manutenção da coerência e da unidade do direito internacional, pois claramente evita contradições e, portanto,

24 CARO, Ernesto J. Rey. La solución de controversias en los procesos de integración en América. El MERCOSUR. Córdoba: Marcos Lerner Editora, 1998, p. 81.

25 A controvérsia que foi objeto do quarto laudo arbitral do sistema de solução de controvérsias do Protocolo de Brasília (Exportação de frangos inteiros) foi posteriormente levada pelo Brasil ao mecanismo da Organização Mundial do Comércio.

26 Tanto o $3^{\circ}$ como o $4^{\circ}$ laudos arbitrais proferidos pelos Tribunais Ad Hoc na vigência do Protocolo de Brasília reconheceram a primazia do direito regional do MERCOSUL sobre o direito internacional comercial geral. 
percepções fragmentadas de um sistema uno.

Quanto aos aspectos procedimentais, cabe à parte reclamante escolher o foro que melhor lhe convier, mas não existe impedimento à escolha convencional e, de qualquer forma, o escolhido se torna imediatamente prevento. No procedimento de Olivos, o início das negociações diretas previstas nos artigos 4 e 41 do protocolo já configura escolha pelo mecanismo regional ${ }^{27}$, ao passo que a escolha do sistema da OMC se dá apenas quando houver requerimento de instauração de painel.

\subsection{O Procedimento de Olivos}

Os procedimentos estabelecidos pelo Protocolo de Olivos e por seu regulamento ${ }^{28}$ apresentam às partes litigantes, além da via jurisdicional, opções diplomáticas e políticas para a solução das controvérsias na esfera regional. As vias não jurisdicionais são, inclusive, privilegiadas pelo mecanismo por constituírem meio mais harmônico para a solução de litígios e, portanto, mais compatíveis com movimentos de integração regional.

\subsubsection{Procedimento Iniciado por Estado}

Os estados devem, primeiramente, conforme disposto no artigo 4 do protocolo, recorrer às negociações diretas, via de regra por meio dos coordenadores regionais do GMC ou representantes designados, durante os quinze dias contados da data de início do procedimento ${ }^{29}$. As negociações diretas caracterizam a opção diplomática apresentada pelo protocolo para a solução de controvérsias entre os estados.

As partes litigantes podem, de comum acordo e caso a fase obrigatória de negociações diretas não prospere, submeter a questão à conciliação conduzida pelo Grupo Mercado Comum - GMC - que deve adotar recomendações ${ }^{30}$ por consenso para que o estado faltante se enquadre à normativa regional, caso as investigações concluam pela procedência do petitório do requerente. A possibilidade do órgão executivo do MERCOSUL atuar na solução de litígios configura meio político de solução de litígios no âmbito do Protocolo de Olivos.

No caso de impossibilidade de solucionar o litígio por meio diplomático, nas negociações diretas, ou político, pela intervenção do GMC, restam ainda os meios jurisdicionais de solução de controvérsias

27 Inciso 3, artigo 1 da Decisão no. 37/03 do Conselho do Mercado Comum dispõe, "in verbis": "Entende-se que um Estado-parte optou pelo sistema de solução de controvérsias do Protocolo de Olivos ao solicitar o início dos procedimentos previstos nos artigos 4 e 41 ".

28 Decisão no. 37/03 do Conselho do Mercado Comum.

29 A redação do inciso 1 do artigo 5 do Protocolo de Olivos corrigiu a dificuldade que havia em se constatar o início da contagem do prazo e estabeleceu contagem a partir da data em que uma das partes comunicou à outra, formalmente, sua decisão de iniciar a controvérsia.

30 Inciso 1, artigo7 Olivos 
previstos no Protocolo de Olivos.

A principal característica desta fase em relação às anteriores é seu caráter eminentemente jurídico, mas nada impede que os estados encontrem uma solução diplomática para a controvérsia, mesmo após o início do procedimento arbitral. A submissão à via jurisdicional já representa, entretanto, exemplo de primazia do direito regional sobre os interesses políticos dos litigantes.

Dois caminhos são apresentados pelo Protocolo de Olivos para a apreciação jurisdicional de um litígio regional. A reclamação pode tanto ser submetida a um Tribunal Arbitral Ad Hoc, como, no caso de decisão conjunta das partes da controvérsia, ser diretamente submetida ao Tribunal Permanente de Revisão do MERCOSUL, que atuará com as mesmas competências de um Tribunal Ad Hoc.

A submissão à jurisdição dos Tribunais Ad Hoc e Permanente de Revisão é obrigatória e decorre do artigo 33 do Protocolo de Olivos. Ressalte-se, conforme já mencionado anteriormente, que o novo mecanismo introduziu a possibilidade de recurso das decisões prolatadas pelos Tribunais Ad Hoc ao conferir competência recursal ao Tribunal Permanente de Revisão do MERCOSUL.

\subsubsection{Procedimento Iniciado por Particular}

O Protocolo de Olivos não apresentou mudanças significativas ao acesso de particulares ao sistema de solução de litígios regional. Tem-se um modelo especial de proteção diplomática - que pode vir a ser exercida pelo estado de domicílio - e não há, portanto, acesso direto de particular ao sistema. O particular interessado deve, primeiramente, submeter à Seção Nacional do Grupo Mercado Comum de sua residência ${ }^{31}$ reclamação formal com a descrição dos fatos e fundamentos jurídicos ${ }^{32}$.

Quanto aos aspectos formais da reclamação, o Regulamento do Protocolo de Olivos estabeleceu em seu artigo 46, letras "c" e "d", os requisitos do petitório, que deve ser sempre impreterivelmente instruído com a prova do prejuízo sofrido e demonstrar o nexo de causalidade entre o mesmo e a violação incorrida.

Uma vez acolhida a pretensão pela Seção Nacional, começa o procedimento de consulta à Seção Nacional do GMC do estado reclamado para que se encontre, no prazo de quinze dias, uma solução

31 O inciso 1 do artigo 40 do Protocolo de Olivos dispõe quanto "residência habitual" e "sede de seus negócios" esclarecendo dúvidas relacionadas ao termo "particular" e abrangendo tanto as pessoas físicas quanto as jurídicas.

32 Esse procedimento é exatamente igual àquele previsto no Protocolo de Brasília, o qual foi descrito por MAGALHÃES, José Carlos de. "Os laudos arbitrais proferidos com base no protocolo de Brasília para a solução de controvérsias”. In: MARTINS, Pedro A. Batista \& GARCEZ, José Maria Rosani (ed.). Reflexóes sobre Arbitragem: in memoriam do desembargador Cláudio Vianna de Lima. São Paulo: LTr, 2002, p. 513. 
diplomática para o litígio, conforme estabelecido no artigo 41 . Na impossibilidade de se encontrar uma solução diplomática, dá-se início à fase política do procedimento com envio da reclamação para o Grupo Mercado Comum.

$\mathrm{O}$ início da fase política marca também o fim da participação direta do particular no procedimento, que, a partir desse momento, poderá apenas desistir da reclamação. O prosseguimento da reclamação dependerá, portanto, da vontade política da parte e os procedimentos seguem aqueles previstos para reclamações feitas pelos estados, inclusive no que diz respeito aos procedimentos jurisdicionais.

Algumas questões importantes surgem no que se refere às reclamações iniciadas por particulares. A primeira delas diz respeito à possibilidade de o particular provocar o mecanismo de solução de controvérsias do MERCOSUL contra ato do próprio estado de sua residência habitual.

A doutrina não é coesa no que se refere a esse aspecto, tendo em vista que a questão envolve a caracterização ou não do acolhimento da reclamação do particular pela Seção Nacional do GMC como proteção diplomática.

Os que reconhecem a proteção diplomática no acolhimento da reclamação sustentam seus argumentos na indiscutível opção feita no MERCOSUL pela intergovernabilidade, a qual se sustenta no direito internacional público geral, e afastam definitivamente a possibilidade de o particular provocar o sistema de solução de controvérsias do MERCOSUL contra seu próprio estado.

É de se ressaltar, ainda, que a caracterização da atuação da Seção Nacional como proteção diplomática e não como atividade vinculada à administração dá ao estado discricionariedade para acolher ou não a reclamação. Já no caso de ser considerada atividade vinculada, não caberia a Seção Nacional fazer qualquer juízo de valor, devendo, portanto, simplesmente acolher e dar prosseguimento à reclamação que houver sido devidamente instruída.

Outra questão importante diz respeito ao ato em si, tendo em vista a necessidade da normativa regional supostamente violada estar plenamente em vigor e conferir, portanto, direitos subjetivos ao particular. Não havendo dúvidas nesse sentido, restaria ao particular a possibilidade de levar sua reclamação ao sistema de solução regional ou de submeter a questão ao poder judiciário de sua residência habitual.

A existência de mais de uma via para a solução do litígio traz à tona, ainda, a questão da prevenção do primeiro que for acionado, que faz com que a reclamação só seja recebida pelo sistema regional se esgotados os procedimentos internos para impedir o trâmite paralelo de ações idênticas. Conforme esse entendimento, o particular só pode reclamar contra estado no sistema de solução de controvérsias do MERCOSUL se não houver ajuizado ação pela via judiciária regular ou, 
caso o tenha feito, após o trânsito em julgado da mesma.

\subsection{Os Tribunais Ad Hoc}

O Protocolo de Olivos manteve as linhas gerais do procedimento arbitral ad hoc contido no Protocolo de Brasília e estabeleceu seu início por meio da notificação à Secretaria do MERCOSUL ${ }^{33}$ da decisão de recorrer à arbitragem "quando não tiver sido possível solucionar a controvérsia mediante a aplicação dos procedimentos referidos nos capítulos IV e V"34 do protocolo, os quais regem os meios diplomático e político de solução de litígios.

O Tribunal Ad Hoc é composto por três árbitros e constitui-se com a indicação de cinco, sendo que dois deles tornam-se suplentes. Dois são indicados por cada uma das partes litigantes e o quinto por consenso. Caso a indicação não ocorra no prazo de quinze dias, o protocolo estabelece a realização de um sorteio entre os nomes constantes na lista registrada na Secretaria do MERCOSUL.

O Tribunal Ad Hoc pode realizar reuniões em qualquer um dos estados e é constituído para julgar controvérsias específicas, dissolvendose tão logo a questão em litígio seja solucionada. Os honorários dos árbitros correm por conta de quem os designou.

No que tange ao objeto das controvérsias, a regra do artigo 14 do protocolo determina que sua fixação se dê nas alegações iniciais apresentadas pelo reclamante e na resposta do reclamado, não podendo ser alterado posteriormente.

Ainda sobre a competência dos Tribunais Ad Hoc, o Protocolo de Olivos instituiu a possibilidade de adoção de medidas preventivas nos casos em que houver perigo de danos graves e irreparáveis a uma das partes na controvérsia. Esse procedimento está previsto no artigo 15 do protocolo.

\subsection{O Tribunal Permanente de Revisão}

O Tribunal Permanente de Revisão do MERCOSUL e sua competência recursal, a qual pode ser extraída de seu próprio nome, são ao mesmo tempo protagonistas da maior inovação do Protocolo de Olivos e alvos das críticas mais contundentes.

O órgão jurisdicional tem sede na cidade de Assunção, capital da República do Paraguai, e foi criado para atuar principalmente como instância revisora das decisões proferidas pelos Tribunais Arbitrais Ad Hoc, mas pode atuar também como tribunal de primeira instância.

33 Em vista da progressiva transformação da Secretaria Administrativa do MERCOSUL em uma Secretaria Técnica, o órgão será referido neste trabalho como "Secretaria do MERCOSUL" consoante autorização contida no artigo 6 da Decisão 30/02 do Conselho do Mercado Comum. 34 Inciso I, artigo 9 do Protocolo de Olivos. 
O Tribunal é composto por cinco árbitros e respectivos suplentes sendo que cada estado indica um árbitro e o quinto é escolhido por consenso. Observa-se que o Protocolo de Olivos II permitirá a designação de árbitros por novos estados que ingressem na organização regional - questão hoje urgente dada a conclusão do ingresso da Venezuela ao MERCOSUL. Os honorários dos árbitros correm por conta de todos em partes iguais e por meio da constituição de um fundo comum, conforme regulamentado pela Decisão 17/04 do Conselho do Mercado Comum.

Referido fundo, por anos administrado ainda pela Secretaria do MERCOSUL já sob o Protocolo de Olivos, foi finalmente transferido por decisão do Conselho do Mercado Comum ao Tribunal Permanente de Revisão em dezembro de $2015^{35}$. A gestão do fundo em Montevideo dificultava o funcionamento do sistema de solução de controvérsias por razoes de comunicação e logística. Era conveniente como um rinoceronte de Java na Sibéria.

Não existe rigidez procedimental e os árbitros devem apenas observar o modelo instituído pela Decisão do Conselho do Mercado Comum 30/04, mas podem adotar suas próprias regras, desde que não atentem contra o estabelecido no Protocolo de Olivos.

\subsubsection{Competências do Tribunal Permanente de Revisão}

\subsubsection{Competência Concorrente}

Finda a fase política, realizada no âmbito do Grupo Mercado Comum, sem que a controvérsia tenha sido solucionada, a reclamação poderá ser levada à fase jurisdicional prevista no Protocolo de Olivos, que, conforme anteriormente mencionado, dá duas alternativas às partes litigantes.

A reclamação poderá ser submetida a um Tribunal Arbitral Ad Hoc, o qual deverá ser constituído especialmente para analisar o litígio, mas as partes podem, entretanto, decidir pela submissão da controvérsia diretamente ao Tribunal Permanente de Revisão, que nesses casos funciona como instância única e assimila, dessa forma, as competências de um Tribunal Arbitral Ad Hoc, como expressamente estabelecido no artigo 23, I, que trata do "acesso direto".

Para que o Tribunal Revisor funcione como primeira instância há de se ressaltar, ainda, a necessidade de consenso entre as partes litigantes e requerimento expresso nesse sentido, o que consagra, a nosso ver, a instituição de Tribunais Arbitrais Ad Hoc como procedimento padrão do sistema de solução de controvérsias do MERCOSUL ${ }^{36}$.

35 MERCOSUL/CMC/DEC 51/15.

36 No Laudo 01/2012 houve negativa de acesso direto ao TPR justamente com base na falta de acordo expresso nesse sentido. 


\subsubsection{Competência de Revisão}

A configuração dos Tribunais Arbitrais Ad Hoc como padrão para a solução de litígios no sistema de solução de controvérsias do MERCOSUL mostra-se fundamental para o funcionamento do Tribunal Permanente de Revisão como instância recursal, principal diferença entre o procedimento previsto no Protocolo de Olivos e aquele consagrado anteriormente no Protocolo de Brasília.

$\mathrm{O}$ mecanismo anterior não previa a possibilidade de revisão e o laudo prolatado fazia coisa julgada, podendo apenas ser objeto de um pedido de interpretação ou aclaramento e de anulação, em caso específico de irregularidades quanto aos árbitros, ambos procedimentos ainda válidos na vigência do Protocolo de Olivos.

Com a entrada em vigor do Protocolo de Olivos e em observância ao disposto em seu capítulo VII, quando prolatado laudo arbitral por Tribunal Arbitral Ad Hoc as partes litigantes podem, individualmente, submetê-lo ao Tribunal Permanente de Revisão, que atuará de forma semelhante a de um órgão de apelação.

Como instância revisora o Tribunal Permanente de Revisão deve atuar em cada caso específico com três árbitros, sendo dois de nacionalidade das partes litigantes e o terceiro indicado por sorteio entre os árbitros restantes de nacionalidades distintas daquelas das partes envolvidas. $\mathrm{O}$ terceiro árbitro será sempre o presidente.

Não cabem alegações de fato ou apresentação de novas provas no procedimento de revisão. As partes poderão recorrer do laudo no que se refere às questões de direito, inclusive hermenêutica. $O$ procedimento consagra o contraditório e há, portanto, possibilidade de contestação das alegações apresentadas.

O Tribunal deve decidir no prazo de trinta dias, prorrogáveis por mais quinze, e por maioria absoluta pela confirmação, modificação ou revogação dos fundamentos jurídicos e das decisões do Tribunal Ad Hoc. Não há possibilidade de recurso da decisão e o único recurso posterior que resta é o de esclarecimento ${ }^{37}$.

O recurso de revisão do capítulo VII do protocolo se limita à análise das questões de direito tratadas na controvérsia e às interpretações jurídicas desenvolvidas no laudo. Completamente excluídas do procedimento de revisão estão as decisões proferidas pelos Tribunais Ad Hoc com base na equidade e os laudos prolatados pelo Tribunal Permanente de Revisão no âmbito do procedimento de acesso direto do artigo 23 de Olivos.

Esgotada essa fase, definitivamente recursal, o laudo faz coisa julgada e deve ser cumprido pelas partes na forma determinada pelos árbitros e eventualmente modificadas pelo Tribunal Permanente de

37 Artigo 23 do Protocolo de Olivos. 
Revisão. Divergências quanto ao não cumprimento podem, entretanto, ser objeto de um novo procedimento arbitral.

Até o momento, duas controvérsias foram resolvidas na vigência do Protocolo de Olivos. Ambas foram inicialmente levadas à apreciação de Tribunais Ad Hoc e objeto do procedimento de revisão pelo Tribunal Permanente de Revisão do MERCOSUL. Mais uma vez ressalta-se a incompatibilidade existente entre a possibilidade de recurso e a celeridade característica dos procedimentos arbitrais ${ }^{38}$.

\subsubsection{Competência Consultiva}

O Protocolo de Olivos outorgou ao Conselho do Mercado Comum, em seu artigo 3, a faculdade de criar "mecanismos relativos à solicitação de opiniões consultivas ao Tribunal Permanente de Revisão". Ainda conforme o disposto no protocolo, a definição do alcance do resultado das consultas e dos próprios procedimentos consultivos seriam instituídos por meio de direito derivado, o que tomou forma na decisão 37/03 do Conselho que, em seu capítulo II, tratou das opiniões consultivas.

Embora a referida decisão também tenha legitimado os membros do MERCOSUL e seus tribunais superiores, apenas os órgãos da organização de integração com capacidade decisória possuem legitimidade plena para provocar a consulta ao Tribunal Permanente.

No caso dos estados, esses não se encontram legitimados para isoladamente requerer opiniões consultivas. Sua legitimidade ativa se dá apenas quando atuarem de forma conjunta, ou seja, por meio de consenso quanto ao objeto e ao conteúdo da consulta, que deve ser apresentada ao Tribunal Permanente de Revisão pela Presidência Pró Tempore.

Já os tribunais superiores nacionais têm legitimidade ativa apenas no que se refere às questões relacionadas com causas que estejam em tramitação em suas esferas jurisdicionais internas. A legitimidade é, de fato, das cortes, mas a regulamentação interna que cada judiciário fez do acesso ao procedimento acabou tendo um resultado inesperado: $\mathrm{o}$ acesso de indivíduos ao sistema de solução de controvérsias do MERCOSUL.

Atualmente, portanto, nos quatro estados, nos quais o encaminhamento de opiniões consultivas ao Tribunal Permanente de Revisão foi regulamentado, qualquer pessoa - física ou jurídica - que for parte de demanda em curso internamente que trate do direito do MERCOSUL pode solicitar - nos termos de cada uma das normativas internas - consulta ao órgão jurisdicional regional máximo. Mais que qualquer outro órgão do MERCOSUL, seja a secretaria do MERCOSUL, o Instituto Social do MERCOSUL ou qualquer outra institucionalidade

38 No caso do atual mecanismo de solução de litígios do MERCOSUL existe a possibilidade de, incluídos os recursos de esclarecimento do artigo 28 do Protocolo de Olivos, serem prolatados quatro pronunciamentos arbitrais sobre a mesma controvérsia. 
existente hoje, o Tribunal Permanente de Revisão é a única instituição regional que possui, por meio das opiniões consultivas, acesso direto, pleno e regulamentado de indivíduos à organização regional.

No que se refere à forma, o Tribunal Permanente de Revisão deve fundamentar sua opinião na normativa mencionada no artigo 34 do Protocolo de Olivos, que abrange todas as fontes originárias e derivadas do MERCOSUL e "os princípios e disposições de Direito Internacional".

Outro ponto importante a ser ressaltado diz respeito aos efeitos, ou melhor, à falta de efeitos vinculantes ou obrigatórios relacionados ao conteúdo das opiniões emitidas pelo Tribunal Permanente. As opiniões emitidas devem servir apenas para orientar a aplicação do direito regional.

É de se observar que a opção política pela não vinculação do judiciário dos estados à interpretação feita pelo Tribunal Permanente reflete a latente resistência dos signatários do Tratado de Assunção a qualquer inovação com características supranacionais. O MERCOSUL perdeu a oportunidade de transformar o procedimento de consulta criado em Olivos e regulamentado pela decisão 37/03 do Conselho do Mercado Comum em um instrumento de afirmação da primazia do direito regional sobre o local.

A participação mais afirmativa do judiciário dos estados no processo regional, mais que um anseio, constitui verdadeira necessidade ${ }^{39}$.

\subsubsection{Medidas Provisionais e Procedimento Excepcional de Urgência}

O Protocolo de Olivos instituiu, em seu artigo 24 a possibilidade de o Tribunal Permanente de Revisão decidir pela adoção de medidas provisionais em atendimento a requerimento feito por estado em casos excepcionais.

A medida de urgência adotada deve ser necessariamente proporcional ao dano demonstrado e imediatamente cumprida pela parte indicada pelo tribunal. As medidas podem ser adotadas no curso de um procedimento arbitral ordinário ou como demanda própria - pelo procedimento excepcional de urgência regulamentado pela Decisão CMC 23/04.

O procedimento autônomo excepcional deve cumprir os requisitos estabelecidos pela referida normativa e o estado requerente deverá demonstrar, por exemplo e conforme disposto no artigo $2^{\circ}$, a relevante urgência, o descumprimento de normativa do MERCOSUL, a iminência do dano e que o mérito envolvido não é objeto de controvérsia em curso.

Da decisão do tribunal cabe pedido de reconsideração, mas não existe recurso cabível no caso de denegação da medida de urgência, sendo que, nesse caso, nada impede que o estado requerente inicie o procedimento regular de solução de controvérsias com o mesmo objeto

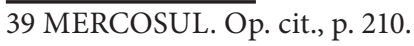


do pedido de medida de urgência ${ }^{40}$.

Como liminar, a adoção de medida deve ser requisitada após iniciado o procedimento regular de solução de controvérsias mediante demonstração de necessidade. Nesse caso, a medida terá caráter provisório consoante disposto no artigo 15 do Protocolo de Olivos, o qual também se aplica aos Tribunais Ad Hoc.

Não há previsão no Protocolo ou no regulamento de medida a ser tomada no caso de o estado beneficiado pela medida provisional ter, posteriormente, decisão contrária no momento de análise do mérito.

\section{LAUDOS}

Todos os laudos prolatados no mecanismo de solução de controvérsias do MERCOSUL devem obedecer às regras estabelecidas no Protocolo de Olivos e na Decisão 37/03 do Conselho do Mercado Comum, seu regulamento de aplicação.

Dentre os aspectos importantes relacionados às características dos laudos encontra-se a necessidade de fundamentação no direito aplicável, ou seja, nas fontes jurídicas do MERCOSUL - o Tratado de Assunção e seus Protocolos posteriores, a normas no âmbito dos órgãos da organização de integração e os princípios gerais de direito internacional.

O caráter eminentemente intergovernamental do MERCOSUL repercute diretamente no sistema de solução de controvérsias, já que a falta de coercibilidade se contrapõe ao ilícito internacional configurado pelo não cumprimento do laudo proferido. Ressalte-se, portanto, que o cumprimento da decisão constante no laudo é obrigatória para a parte requerida, não havendo, dessa forma, possibilidade de o estado optar pelo descumprimento.

Ainda que exista a possibilidade de utilização dos princípios gerais do direito para fundamentar a decisão, o que pode auxiliar a supressão de possíveis lacunas no ordenamento regional, os árbitros deverão limitar suas decisões às questões de direito, não competindo aos mesmos, por exemplo, indicar a forma de aplicação da decisão ou declarar revogadas as medidas contestadas.

Por fim, cumpre ressaltar que os laudos não criam jurisprudência, mas podem servir de referência aos árbitros que decidirem em laudos posteriores, e não vinculam necessariamente o poder judiciário nacional, sendo que subsiste a possibilidade de haver reconhecimento dessa vinculação pelo juízo interno dos estados.

40 O procedimento excepcional de urgência foi utilizado pela República do Paraguai em 2012 para questionar sua suspensão da participação nos órgãos decisórios do MERCOSUL e o ingresso da República Bolivariana da Venezuela na organização. O requerimento foi rejeitado por não cumprir os requisitos estabelecidos na decisão 23/04. 


\subsection{O Controle do Cumprimento}

O mecanismo previsto no Protocolo de Olivos introduz, em seu artigo 30, a possibilidade de realização de um procedimento de análise do cumprimento do laudo que houver feito coisa julgada.

Conforme o disposto no mencionado artigo do protocolo, a parte que houver tido sua reclamação reconhecida pelo laudo arbitral poderá requerer ao tribunal que prolatou o laudo, no caso o Tribunal Ad Hoc constituído ou o Tribunal Permanente de Revisão quando houver funcionado como instância única, que se pronuncie quanto ao efetivo cumprimento do laudo.

A composição do tribunal repete, via de regra, aquela que houver proferido o laudo e o pronunciamento deve ocorrer no prazo de trinta dias. Caso o tribunal competente reconheça em seu pronunciamento o cumprimento dos ditames do laudo proferido, o estado requerente não poderá adotar medidas compensatórias contra o estado que julgava faltante.

Se o tribunal competente, entretanto, decidir que o estado requerido não cumpriu as determinações do laudo proferido, as quais se encontrava obrigado, o mesmo deverá cumprir imediatamente os termos do laudo de forma a evitar que o estado requerente aplique medidas compensatórias para coibir o cumprimento.

\section{MEDIDAS COMPENSATÓRIAS}

Como mencionado anteriormente, o estado requerente poderá adotar medidas compensatórias para induzir o estado faltante a acatar as determinações do laudo prolatado. O Protocolo de Olivos por um lado corrigiu uma falha do mecanismo do Protocolo de Brasília ao regulamentar a aplicação de medidas compensatórias no mecanismo de solução de controvérsias do MERCOSUL, mas criou, por outro lado, possibilidade perigosa no âmbito de um acordo de integração regional.

A controversa hipótese encontra-se disposta do artigo 31 do Protocolo de Olivos ${ }^{41}$ que permite à parte beneficiada pelo laudo arbitral a adoção de medidas compensatórias independentemente de provocação do procedimento de verificação do cumprimento da decisão e mesmo paralelamente a sua instauração.

O dispositivo mencionado estabelece a possibilidade de adoção de tais medidas pelo prazo de um ano contado a partir do dia seguinte do prazo estabelecido no laudo para o cumprimento de suas determinações.

Cumpre ressaltar, entretanto, que no caso de instauração de procedimento de verificação do cumprimento do laudo e de posterior decisão que reconheça seu efetivo cumprimento, o estado que tiver

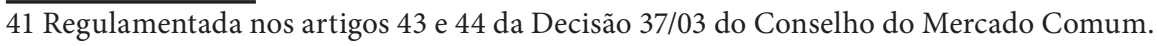


adotado medidas compensatórias deverá retirá-las imediatamente.

As medidas compensatórias consistem basicamente na suspensão de obrigações assumidas no âmbito do acordo regional que sejam do interesse do estado supostamente faltante e devem necessariamente incidir sobre o mesmo setor envolvido no litígio, não havendo, portanto, a possibilidade de aplicação de medidas compensatórias cruzadas, ou seja, em setores não envolvidos na controvérsia objeto do laudo.

O estado obrigado a cumprir o laudo deverá ser informado com antecedência de quinze dias do início da aplicação da medida que deverá ter caráter temporário. A temporalidade decorre da natureza das medidas compensatórias no sistema de solução de controvérsias do MERCOSUL, as quais possuem finalidade única de compelir o estado supostamente faltante a cumprir o laudo arbitral. As medidas compensatórias regulamentadas no Protocolo de Olivos não possuem caráter sancionatório, reflexo das próprias características do acordo regional.

As medidas compensatórias devem, além disso, ser proporcionais ao dano provocado pelo não cumprimento da decisão do laudo e, além de devidamente justificadas, seguir necessariamente os critérios dispostos no artigo 32 do Protocolo de Olivos.

A adoção de medidas desproporcionais e em desacordo com os critérios do protocolo poderá dar ensejo à solicitação, pelo estado interessado, de manifestação do tribunal que tenha prolatado o laudo quanto à proporcionalidade das medidas, não havendo, entretanto, previsão de suspensão de aplicação das mesmas.

De qualquer forma, faz-se necessário ressaltar que a aplicação de medidas compensatórias vai de encontro às características essenciais de uma organização de integração, como, por exemplo, a não-discriminação contida na livre circulação de bens, serviços e fatores produtivos elencada entre os propósitos e princípios do artigo 1 do Tratado de Assunção que criou o MERCOSUL.

\section{CONCLUSÃO}

A importância de se instituir um sistema de solução de controvérsias como forma de se consolidar a integração regional foi reconhecida pelos membros na gênese do MERCOSUL por meio da adoção do anexo III do Tratado de Assunção, que instituiu o primeiro sistema de solução de controvérsias da organização.

A precariedade do mecanismo original, o qual nunca foi utilizado, foi logo substituída pelas regras do Protocolo de Brasília que, baseado na arbitragem ad hoc, cumpriu de forma exemplar sua função no contexto regional. Os procedimentos adotados em Brasília foram mantidos inclusive após a entrada em vigor do Protocolo de Ouro Preto, o qual estabeleceu a configuração institucional definitiva do MERCOSUL. 
O Protocolo de Brasília foi revogado pela entrada em vigor do Protocolo de Olivos em 2002, regulamentado pela decisão 37/03 do Conselho do Mercado Comum. Dentre as inovações trazidas por Olivos, destacam-se a possibilidade de eleição de foro e a criação do Tribunal Permanente de Revisão.

O Protocolo de Olivos outorga legitimidade ativa aos estados, de forma direta e sem a necessidade de demonstração de prejuízo. Como hipótese meramente teórica, também dá legitimidade aos particulares que apenas indiretamente - representados por estado - e mediante prova do prejuízo e nexo de causalidade entre o mesmo e a violação apontada podem provocar a competência litigiosa do sistema. No que se refere ao objeto, o protocolo abrange todos os litígios relacionados a obrigações previstas em qualquer uma das fontes jurídicas do MERCOSUL, sejam elas originárias ou derivadas.

O atual sistema conserva os Tribunais Ad Hoc como a forma padrão para a solução de litígios no âmbito regional e prevê a possibilidade de revisão do laudo pelo Tribunal Permanente de Revisão, que, por sua vez, só pode funcionar com a competência das cortes ad hoc - acesso direto - se houver consenso entre as partes litigantes. Além das mencionadas competências concorrente e de revisão, o Tribunal Permanente de Revisão possui legitimidade para, mediante consulta, adotar opiniões, sem efeitos obrigatórios, relacionadas à interpretação do direito regional e podem ainda, em caráter excepcional, adotar medidas provisionais mediante demonstração de iminência de dano. Quanto às opiniões consultivas, importante se faz ressaltar, também, o amplo acesso de particulares por meio dos tribunais superiores dos estados.

$\mathrm{Na}$ primeira parte do trabalho, a eficácia das normas internacionais foi apresentada como tema para reflexão e o papel dos tribunais internacionais ganhou importante relevo. Um panorama histórico do sistema de solução de controvérsias do MERCOSUL foi apresentado em seguida para introduzir os aspectos mais dogmáticos de seu funcionamento atual. Os contornos dos laudos arbitrais foram objeto da parte seguinte que antecedeu análise, igualmente dogmática, das chamadas medidas compensatórias permitidas pelo mecanismo.

Apesar das críticas ao Protocolo de Olivos, a solução de controvérsias no MERCOSUL operou até o momento com sucesso surpreendente a eficácia incontestável. Na vigência do Protocolo de Brasília, por exemplo, todos os dez laudos arbitrais prolatados foram devidamente cumpridos pelos estados reclamados. Na vigência de Olivos, a existência de uma instância arbitral permanente e o acesso de indivíduos à competência consultiva do sistema são os pontos mais marcantes. $\mathrm{Na}$ iminente vigência de Olivos II e no fortalecimento institucional do órgão máximo do sistema solução de controvérsias regional encontram-se depositadas as expectativas atuais de coesão e 
coerência do direito do MERCOSUL.

REFERÊNCIAS BIBLOGRÁFICAS

ACCIOLY, Hildebrando. Manual de direito internacional público. São Paulo: Saraiva, 1972.

BAPTISTA, Luiz Olavo. "As solucões de divergências no MERCOSUL". In: Basso, Maristela. MERCOSUL seus efeitos jurídicos, econômicos e políticos nos Estados-membros. Porto Alegre: Livraria do Advogado, 1995.

BAPTISTA, Luiz Olavo. O MERCOSUL, suas instituições e ordenamento jurídico. São Paulo: Ltr, 1998.

BAPTISTA, Luiz Olavo. "Sistemas para solução de divergências nas instituições de integração e o MERCOSUL". In: MAGALHÃES, José Carlos \& MERCADANTE, Araminta de Azevedo (ed.). Solução e prevenção de litígios internacionais. Porto Alegre: Livraria do Advogado, 1999.

CARO, Ernesto J. Rey. La solución de controversias en los procesos de integración en América. El MERCOSUR. Córdoba: Marcos Lerner Editora, 1998.

CASELLA, Paulo Borba. MERCOSUL exigências e perspectivas. São Paulo: Ltr, 1996.

CASELLA, Paulo Borba. Direito internacional: vertente jurídica da globalização. Porto Alegre: Síntese, 2000.

CASELLA, Paulo Borba. BRIC: Uma perspectiva de cooperação internacional. São Paulo: Atlas, 2011.

COSTA, Elizabeth Accioly Rodrigues da. "O sistema de solução de controvérsias do MERCOSUL consoante a previsão do artigo 44 do protocolo de Ouro Preto: análise comparativa de sistema de solução de controvérsias em blocos econômicos e propostas para o sistema permanente do MERCOSUL". [Tese de Doutorado]. Faculdade de Direito da Universidade de São Paulo, 2003.

ETCHEVERRY, Raul Aníbal. MERCOSUR negocios y empresas. Buenos Aires: Ciudad Argentina, 2001.

FERRAJOLI, Luigi. A Soberania no Mundo Moderno. São Paulo: Martins Fontes, 2002.

MAGALHÃES, José Carlos de. "Os laudos arbitrais proferidos com base no protocolo de Brasília para a solução de controvérsias". In: MARTINS, Pedro A. Batista \& GARCEZ, José Maria Rosani (ed.). Reflexões sobre Arbitragem: in memoriam do desembargador Cláudio Vianna de Lima. São Paulo: LTr, 2002, p. 513.

MERCADO COMUM DO SUL, MERCOSUL. Primeiro relatório 
sobre a aplicação do direito do MERCOSUL pelos tribunais nacionais. Montevideo: Secretaría do MERCOSUL, 2005.

PEREIRA, Ana Cristina Paulo. Direito institucional e material do MERCOSUL. Rio de Janeiro: Lumen Juris, 2005.

RANGEL, Vicente Marotta. "Solução de controvérsias após Ouro Preto". In: Casella, Paulo Borba (ed.). Contratos internacionais e direito econômico no MERCOSUL após o termino do período de transição. São Paulo: Ltr, 1996.

RUÍZ DIAZ LABRANO, Roberto. Hacia un tribunal de caracter supranacional en el MERCOSUR. Desafíos del MERCOSUR. Buenos Aires: Ciudad Argentina, 1997. 